\title{
Vaginal Leiomyoma- A Diagnostic Dilemma
}

\author{
Srushti Deepak Sakre1, Manisha Manish Laddad², Archana Vinayak Rokade ${ }^{3}$
}

\begin{abstract}
${ }^{1}$ Department of Obstetrics and Gynaecology, Krishna Institute of Medical Sciences, Karad, Maharashtra, India. ${ }^{2}$ Department of Obstetrics and Gynaecology, Krishna Institute of Medical Sciences, Karad, Maharashtra, India. ${ }^{3}$ Department of Obstetrics and Gynaecology, Krishna Institute of Medical Sciences, Karad, Maharashtra, India.
\end{abstract}

\section{INTRODUCTION}

Vaginal leiomyomas are uncommon masses located on the anterior wall of vagina and rarely lateral wall and vulval region. Only 250 and 300 cases have been reported worldwide. These are benign smooth muscle lesions, usually single and mostly without symptoms. The cause is unknown. Histologically, they resemble leiomyoma elsewhere. They originate from smooth muscle cells of vagina, local arterial musculature, or bladder or urethra smooth muscles. These are oestrogen dependent lesions like uterine leiomyomas. They rarely become malignant. Pressure symptoms include discharge per vaginum or bleeding, dyspareunia, or retention of urine. Lesion has to be excised in the symptomatic patient. Recurrence is rare.

\section{PRESENTATION OF CASE}

A 42-year-old married multigravida, farmer by occupation came with complaint of protruding mass below the urethral opening since one year not associated with pain. There were no bowel bladder complaints. Examination findings were a round, hard, painless mass, about 3-4 cm in diameter, was palpable between the urethra and the vaginal. A small extension of mass was protruding through the mass which bled on touch, Patient was investigated on OPD basis. All preoperative investigations were done. USG abdomen pelvis with colour doppler showed uterine prolapse with cystocoele with adnexal vascular congestion. Cystoscopy was planned under anaesthesia.

\section{DIFFERENTIAL DIAGNOSIS}

Urethral diverticulum, fibro epithelial polyp, cystocoele, Skene duct abscess, vaginal malignancy, leiomyoma of anterior vaginal wall.

\section{DISCUSSION}

Vaginal fibroids are benign mesenchymal tumours of the vaginal wall. They are rare. $5 \%$ of periurethral masses are vaginal leiomyoma. These lesions have varying sizes from 1 to $10 \mathrm{~cm}$ in diameter. They mostly present as a firm, smooth, round mass on the vaginal wall. They may be confused with paraurethral cyst or urethral diverticulum. ${ }^{(1)}$ Females in the age group of 35-50 years are prone to develop vaginal leiomyomas. Usually the tumour is solitary and small and grows slowly. As they are oestrogen dependent, they usually grow rapidly during pregnancy or regress after menopause. ${ }^{(2)}$ They show no symptoms most likely or sometimes show symptoms specific to site and size. Symptoms are mass effect, obstruction, pain, and dyspareunia. $^{(3,4)}$
Corresponding Author: Dr. Manisha Manish Laddad, 75/1A, Block, Vithaldev Housing Society, Malkapur-415110, Karad, Maharashtra, India.

E-mail: drmanishald@gmail.com

DOI: $10.14260 / \mathrm{jemds} / 2020 / 130$

Financial or Other Competing Interests: None.

How to Cite This Article:

Sakre SD, Laddad MM, Rokade AV. Vaginal leiomyoma- a diagnostic dilemma. J. Evolution Med. Dent. Sci. 2020;9(08):586587, DOI: $10.14260 /$ jemds/2020/130

Submission 12-03-2019,

Peer Review 27-01-2020,

Acceptance 05-02-2020,

Published 24-02-2020. 


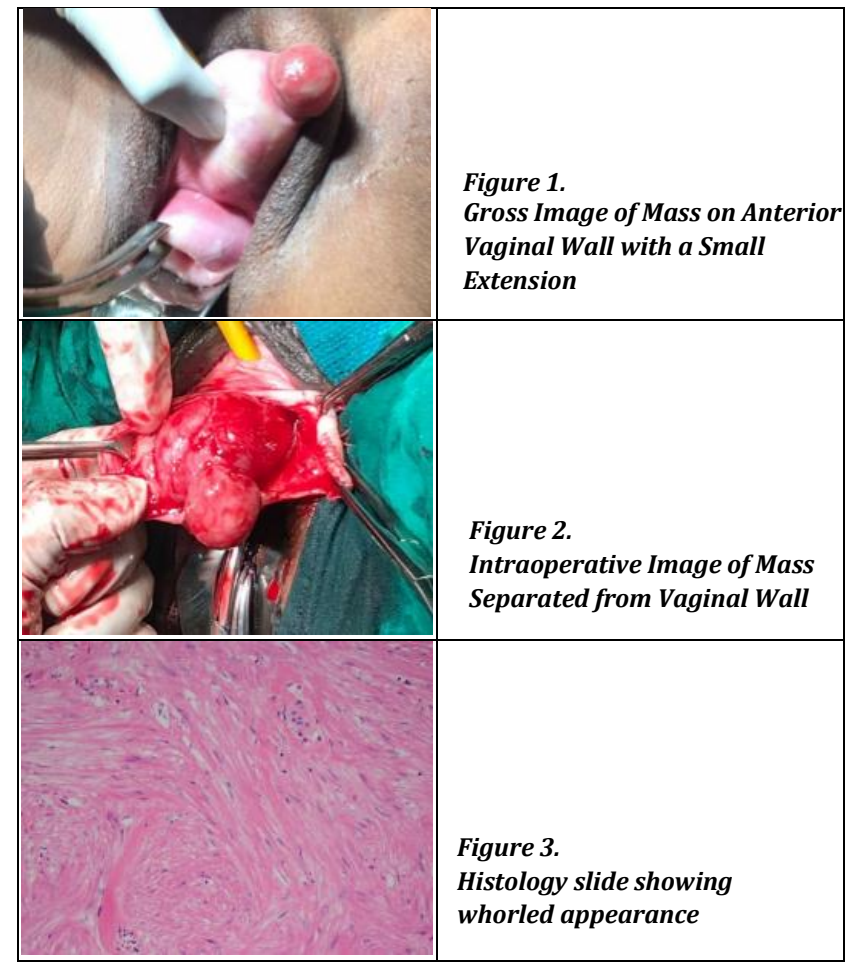

Ultrasound and MRI may help. They tell us about the characteristic and depth of involvement. Vaginal approach is preferred to excise the mass, and this is considered curative and it also help to confirm the diagnosis and rule out malignancy histologically. For large tumours abdominoperineal approach is preferred.

In this case, we had mis-diagnosed this case as a paraurethral mass before operating. However, on HPR the diagnosis was corrected. Patient underwent hysterectomy but there is a possibility that rest vagina might develop leiomyoma. Before surgical intervention, the TVS-guided needle biopsy could help to reach the appropriate diagnosis.

\section{DISCUSSION OF MANAGEMENT}

We posted the patient for evaluation under anaesthesia SOS vaginal hysterectomy SOS abdominal hysterectomy with cystoscopy. A Foley's catheter was introduced in the urethra. Vaginal hysterectomy was carried out for second degree uterine prolapse. Midline incision was given on the anterior vaginal wall. A $3 \mathrm{~cm}$ mass, soft in consistency with a capsule. The tumour appeared separate from the urethra. It was completely confined to the vagina and cervix appeared free. We removed the mass with the capsule and sent it for pathology, which suggested leiomyoma with superficial ulceration and granulation tissue. Extra vaginal wall was cut and cystocoele repair was done. Cystoscopy was done which showed no abnormality. Patient withstood the procedure well. Hospital stay was four days postoperatively. HPR confirmed vaginal leiomyoma.

\section{REFERENCES}

[1] Shah M, Laddad M, et al. Three cases of unusual presentation of fibroid. J Evolution of Med Dent Sci 2018;7(35):3926-8.

[2] Srivastava D, Bhute S, Kakani A, et al. A rare case of vaginal leiomyoma diagnosed postoperatively. J South Asian Fed Obstet Gynaecol 2011;3(3):143-4.

[3] Bae JH, Choi SK, Kim JW. Vaginal leiomyoma: a case report and review of the literature. J Women's Med 2008;1(2):92-3.

[4] Hameed N. Leiomyoma of the vagina. J Ayub Med Coll Abbottabad 2003;15(2):63-4. 